\title{
Relationship between Quality of Building Maintenance Management Services for Indoor Environmental Quality and Occupant Satisfaction: Case Study of Bus Terminal Buildings in Penang
}

\author{
Chong Choon Full ${ }^{1}$, Amin Akhavan Tabassi ${ }^{2, a}$ \\ ${ }^{1,2}$ School of Housing, Building and Planning, Universiti Sains Malaysia, 11800, Penang, Malaysia
}

\begin{abstract}
Maintenance is often defined as the series of activities undertaken to take care of the building structure and services to ensure the intended functions and optimal performance of a building life cycle. The management department of a building is usually responsible for the enhancement of the indoor environment quality by service delivery and for boosting occupant productivity and satisfaction. Thus, a salient point of this study is to determine the current level of the building's maintenance management service for indoor environmental quality in Penang bus terminals, along with its occupant satisfaction with regards to the services provided in the building. The assessment of the indoor environmental quality includes the evaluation of thermal comfort, lighting condition, air quality and cleanliness. Apart from that, qualitative and quantitative methodologies were applied during the process of data collection and analysis. A questionnaire survey was distributed to 500 of the targeted population for each bus terminal, including passengers and the staff. In this study, the conclusion was drawn in which the maintenance management service level of the bus terminal was directly proportional to occupant satisfaction. However, the current quality of maintenance management services in the bus terminals are still not up to the level of the occupants' satisfaction.
\end{abstract}

\section{Introduction}

Every building has its lifespan in which to carry out its intended function. It deteriorates over time, reducing the quality of the building structure, services and facilities. To a more critical extent, a building that is being managed poorly and with improper maintenance will face more damage and costly repair work if left unattended, and eventually endanger the health and safety of the occupants [1]. These phenomena are often seen especially when the building is older and subjected to a longer utilization period.

\footnotetext{
${ }^{a}$ Corresponding author: akhavan@usm.my
} 
To ensure the optimal performance of a building life cycle, maintenance is really essential. The term 'maintenance' is defined as activities undertaken aimed at taking care of the building structure or/and service to ensure that a building serves its intended functions throughout its entire lifespan. These activities occur after the completion or after any repair, refurbishment or replacement to the current standards [2]. It is a continuous activity, not necessarily a contributing factor to the building condition but to ensure that the building performs its functional requirements.

Building maintenance practices are usually discussed in associated with the building fabric component, building services and amenities. The indoor environment of many public buildings, particularly bus terminals in this case, are controlled by building services especially mechanical systems that consume considerable amounts of energy to provide the optimum and favourable indoor environments. Moreover, with the large amount of users in public buildings, the comfort and satisfaction of occupants with regard to the indoor environment becomes more important than before. Building owners and managers need to take extra care to meet the Indoor Environment Quality (IEQ), especially when these issues affect the occupants' health and satisfaction level to the extent of influencing the productivity of office workers [3,4].

A building should always be maintained wisely and positively to create a favourable space for the occupants daily usage. A salient point of this research is that it is based on the idea in which maintenance management services have a behavioural effect on the indoor environments, at the same time introducing the importance of building maintenance management services into bus terminals. Appropriate ways in which these services can be optimized for occupant satisfaction will be suggested as the research outcome. This shows the way to best manage buildings so to improve the indoor environment for the occupants and users as a result of strategic planning.

\section{Methodologies}

Research methodology gives the explanation of the research methods which are used throughout the study to acquire the relevant data for a results analysis later on.

\section{$2.1 \quad$ Investigated Bus Terminals}

Two bus terminals located in Penang were investigated in this study. General information about the two bus terminals is summarized in Table 1 .

Table 1: Characteristics of the investigated bus terminals

\begin{tabular}{|c|c|c|c|c|c|c|}
\hline Building & Location & $\begin{array}{c}\text { Completion } \\
\text { year }\end{array}$ & $\begin{array}{c}\text { Number } \\
\text { of floors }\end{array}$ & $\begin{array}{c}\text { Type of } \\
\text { management }\end{array}$ & $\begin{array}{c}\text { Area inside the } \\
\text { building }\end{array}$ & $\begin{array}{c}\text { Type of bus } \\
\text { services provided }\end{array}$ \\
\hline $\begin{array}{c}\text { Sungai } \\
\text { Nibong } \\
\text { bus } \\
\text { terminal }\end{array}$ & $\begin{array}{c}\text { Penang } \\
\text { Island }\end{array}$ & 2005 & 2 & Outsourcing & $\begin{array}{c}\text { Pick-up area, } \\
\text { waiting area, dining } \\
\text { area, staircase, } \\
\text { corridor, toilet }\end{array}$ & $\begin{array}{c}\text { Acts as main } \\
\text { terminal for } \\
\text { express buses on } \\
\text { Penang Island }\end{array}$ \\
\hline $\begin{array}{c}\text { Penang } \\
\text { Sentral } \\
\text { bus } \\
\text { terminal }\end{array}$ & Butterworth & 2008 & 1 & Direct & $\begin{array}{c}\text { Waiting area, toilet, } \\
\text { escalator }\end{array}$ & $\begin{array}{c}\text { Acts as main } \\
\text { terminal for } \\
\text { express buses and } \\
\text { intercity buses in } \\
\text { Butterworth }\end{array}$ \\
\hline
\end{tabular}

\subsection{Interview}

Interviews were carried out with each administrative person or property manager of the bus terminals. During the interview, the administrative person was asked to answer to the Evaluation Index of Maintenance Management Service Quality, created by the Research Institute of 
Environmental Management, Administration and Maintenance of JAPAN, which is also known as the Takakusagi checklist. Basically, this index is composed of eight parts and 90 questions.

The main purpose of developing this checklist is to evaluate a building's maintenance management service level. It consists of a character as a grading system, where each question has three options of answers, from the highest quality indication by level 1 to the lowest of level 3 with the percentage of selecting level 1 as the final grade. The managers were asked to fill in all the parts of the checklist, where parts 1,4 and 5 were mainly used to correlate occupant satisfaction with the indoor environment in this paper.

\subsection{Visual Inspection}

In order to support the data received through the interview, visual inspection was carried out by the researcher. During the process of visual inspection, the researcher inspected the surrounding building environment of the bus terminals to observe the condition of the building services and to collect data regarding the building maintenance management. Photos of the services were taken as evidence to strengthen the reliability of the explanation stated. However, this visual inspection was limited to only the accessible areas in the bus terminal.

\subsection{Questionnaire Survey}

The main intention of conducting this survey is to determine the occupant satisfaction level in correspondence to the level of maintenance management services of the bus terminal. The target population was 500 respondents consisting of occupants, including passengers and counter staff.

Basically, the questionnaire consisted of mainly four indoor environment parameters i.e. thermal comfort, lighting condition, air quality and cleanliness, with three questions each sub-divided according to the different areas of the bus terminal. The type of questions used was closed ended questions with a five-point Likert scale to get a detailed result regarding the level of occupant satisfaction. In the last section, the respondents could also provide their comments and suggestions which will increase the value of this questionnaire survey.

Meanwhile, the questionnaire was distributed manually, which means the researcher went to the studied bus terminals and asked the occupants to answer the questionnaire directly in person. This minimizes the errors of misinterpretation of the questionnaires and makes the task of explaining to the respondents easier.

\section{Data Collection and Analysis}

The collected data was then being tabulated in figure and table form, which was then further analysed to explain the results of this research.

\subsection{Interview}

By using the Takakusagi tool, the percentage of level 1 responses in the survey was calculated to evaluate the maintenance service levels of both the bus terminals. To calculate these percentages, of answers that chose level 1 were divided by the total number of answers returned. The building that was rated with higher level 1 responses was the Sungai Nibong bus terminal (30.3\%) compared to the Penang Sentral bus terminal (23.5\%). This means that the maintenance management services provided at Sungai Nibong is higher compared to those of the Penang Sentral bus terminal. Figure 1 illustrates the total number of answers returned and percentages of level 1 answered in the survey by the administrative person of both the bus terminals. 


\section{Total number of answers with percentage of level 1 chosen}

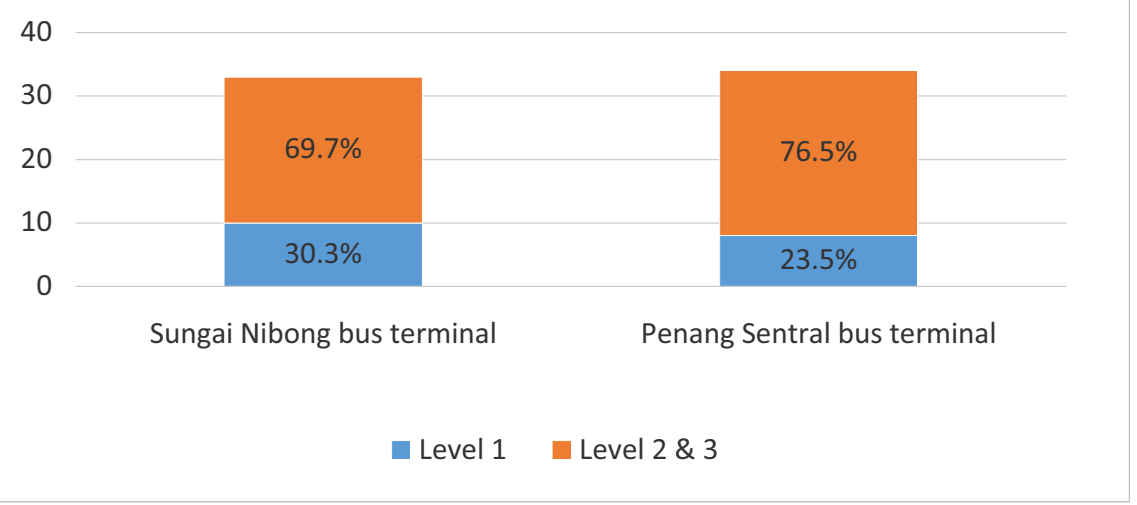

Figure 1: Quality of maintenance management services provided in both the bus terminals

\subsection{Questionnaire}

\subsubsection{Overall Occupant Satisfaction on Indoor Environmental Parameters in the Bus Terminals}

Table 6 shows a summary of the mean values for the overall occupant satisfaction on the four studied indoor environmental parameters in both the investigated bus terminals, and also the overall occupant satisfaction of the bus terminals. According to the results analysed, the first parameter known as thermal comfort has a lower satisfaction in the Penang Sentral bus terminal with a mean index of 2.70 compared to the Sungai Nibong bus terminal with mean index of 3.00. This results show that the respondents are dissatisfied with the overall thermal comfort of the Penang Sentral bus terminal whereas the respondents are neither satisfied nor dissatisfied with thermal comfort of the Sungai Nibong bus terminal.

Table 6: Summary of mean values for overall occupant satisfaction on the indoor environmental parameters in the bus terminals

\begin{tabular}{|c|c|c|}
\hline & Penang Sentral bus terminal & Sungai Nibong bus termina \\
\hline Indoor temperature & 2.71 & 2.98 \\
\hline Indoor humidity & 2.70 & 3.02 \\
\hline (A) Thermal comfort & 2.70 & 3.00 \\
\hline Amount of light & 3.12 & 3.27 \\
\hline Visual comfort & 3.18 & 3.17 \\
\hline (B) Lighting condition & 3.15 & 3.22 \\
\hline Air freshness & 2.50 & 2.86 \\
\hline Air flow & 2.66 & 2.93 \\
\hline (C) Air quality & 2.58 & 2.90 \\
\hline General cleanliness & 2.72 & 2.99 \\
\hline Cleaning service & 2.72 & 3.07 \\
\hline (D) Cleanliness & 2.72 & 3.03 \\
\hline $\begin{array}{l}\text { Overall occupant satisfaction } \\
(A+B+C+D)\end{array}$ & 2.79 & 3.04 \\
\hline
\end{tabular}

The second parameter, lighting condition, has a better level of occupant satisfaction in both bus terminals, recording a mean index of 3.15 in the Penang Sentral bus terminal and 3.22 in the Sungai Nibong bus terminal. Respondents in the Sungai Nibong bus terminal are slightly more satisfied than 
those in the Penang Sentral bus terminal. However, both bus terminals have satisfying levels of lighting condition to an extent.

As for the third parameter of air quality, both the bus terminals record occupant dissatisfaction with the Penang Sentral bus terminal having a lower mean index of 2.58 than the 2.90 of the Sungai Nibong bus terminal. This means that respondents in the Penang Sentral bus terminal are more dissatisfied with the air quality inside the building compared to level of dissatisfaction of the respondents in Sungai Nibong.

The next and last parameter considered is cleanliness, with a mean index of 2.72 in the Penang Sentral bus terminal and 3.03 in the Sungai Nibong bus terminal. This indicates that the respondents of the Penang Sentral bus terminal are dissatisfied with the cleanliness of the building overall; whereas the respondents of Sungai Nibong bus terminal are actually neither satisfied nor dissatisfied with the cleanliness inside the building.

In a nutshell, the overall occupant satisfaction level of the Penang Sentral bus terminal is at a mean index of 2.79 while the Sungai Nibong bus terminal has a mean index of 3.04. This indicates that the respondents are actually dissatisfied with the overall performance of the Penang Sentral bus terminal in terms of indoor environmental quality, whereas the respondents in the Sungai Nibong bus terminal are actually neither satisfied nor dissatisfied with a slight bias to a satisfied level.

\subsection{Visual Inspection}

\subsubsection{Sungai Nibong Bus Terminal}

\subsubsection{Thermal Comfort}

Based on the results, the most satisfied area in terms of thermal comfort inside the Sungai Nibong bus terminal is the dining area. It is an enclosed area with air-conditioning system inside, which adjusts the indoor temperature and humidity to the optimum level as shown in Figure 2 . All the air-conditioning systems are in good operating condition. The most dissatisfied indoor thermal comfort noted is pick-up area. It is mainly due to the exposed condition of the area without any HVAC (Heating, Ventilation and Air Conditioning) control system as shown in Figure 3.

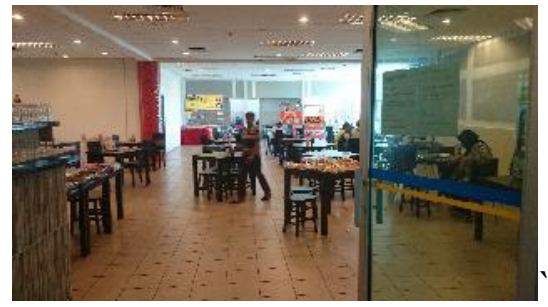

Figure 2: Dining area with air-conditioning system

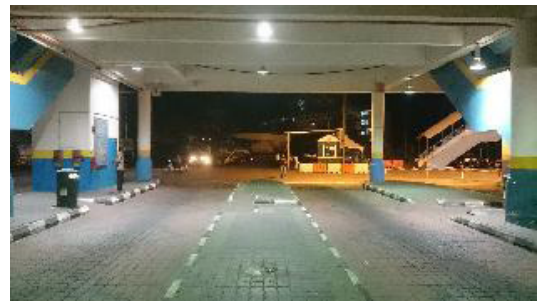

Figure 3: Pick-up area in exposed condition

\subsubsection{Lighting Condition}

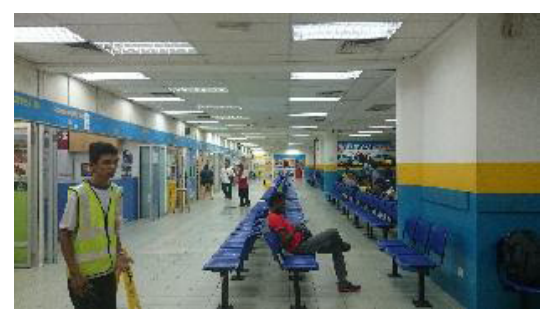

Figure 4: Waiting area in bright condition 
The most satisfied area with regards to lighting conditions inside the Sungai Nibong bus terminal is the waiting area. It has fluorescent lighting systems fixed to a suspended ceiling to provide visibility for the occupants. As shown in Figure 4, all the lighting systems in the waiting area are in good operating condition. As for the most dissatisfied area, malfunctioning lighting systems inside the staircase and corridor area was found during the night hours. This problem should be managed and handled well to prevent any unwanted incidences from arising due to the dim surroundings.

\subsubsection{Air Quality}

According to the data analysed, the dining area has the highest air quality satisfaction inside the bus terminal. Similar to the thermal comfort issue, this was due to the good condition of the HVAC control system implemented inside the area to control the air flow and air freshness. The pick-up area recorded the most dissatisfaction with its air quality assessment because it is exposed to the external environment, open to dust and dirt from the road nearby. In addition, the buses which get into the platform further produce dirty air and smoke which pollute the area and worsen the air quality. Figure 5 shows the buses which access the platform inside the pick-up area causing higher air pollution.

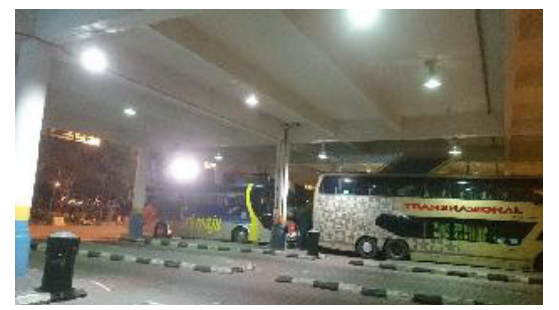

Figure 5: Buses accessing the platforms worsen the air quality

\subsubsection{Cleanliness}

Regarding the issue of cleanliness inside the bus terminal, the waiting area and dining area recorded the most satisfaction. This can be explained by the frequent cleaning services provided inside the building, particularly 2 shifts per day alternatively with 13 cleaners per shift, according to the property manager. The most dissatisfied area is the toilet with a low rating of satisfaction. Throughout the visual inspection, it was observed that the toilet condition inside the bus terminal was pretty bad, in terms of its services and cleanliness. Even though the cleaning services were provided to a large extent, however, facilities were not being properly managed and some were damaged. Figure 6 shows the damage of the handle of a water tap.

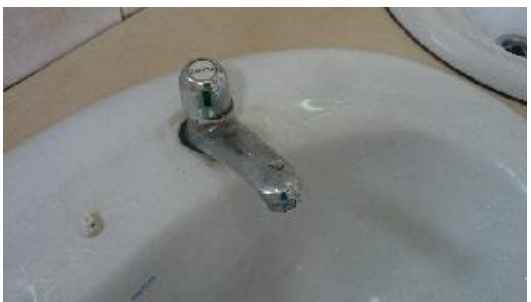

Figure 6: The handle of the water tap is damaged

\subsubsection{Penang Sentral Bus Terminal}

\subsubsection{Thermal Comfort}

For the Penang Sentral bus terminal, thermal comfort seemed to be an issue which needs more attention for occupant satisfaction. This is mainly due to the structure of the building, where the 
building was exposed to the external ground conditions without an enclosed area with an airconditioning system within. The toilet had a quite low level of thermal comfort because it is an enclosed area with only a fan inside to maintain the indoor temperature as shown in Figure 7. The waiting and escalator area are both exposed areas with natural air ventilation within the area. Figure 8 shows the fans used fixed on the columns in waiting area. The escalator had no fans or any HVAC control systems inside, however the area was much more comfortable thermally because the area is an exposed area with natural air ventilation.

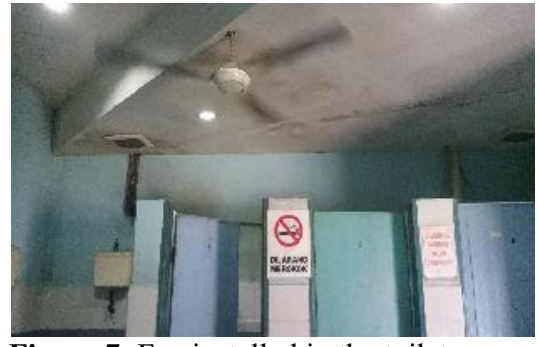

Figure 7: Fan installed in the toilet

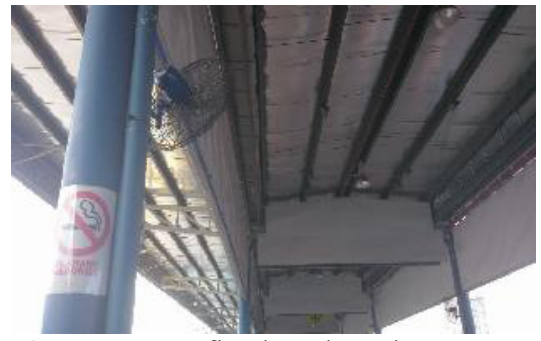

Figure 8: Fans fixed on the column

\subsubsection{Lighting Condition}

In terms of the lighting conditions inside Penang Sentral bus terminal, the area with the highest satisfaction level is the waiting area, while the lowest is the toilet. This can be explained by the exposed condition and the stronger lighting system provided in the waiting area as shown in Figure 9. Meanwhile, the toilet has the lowest satisfaction level because the lighting system implemented was down lights with weaker luminance.

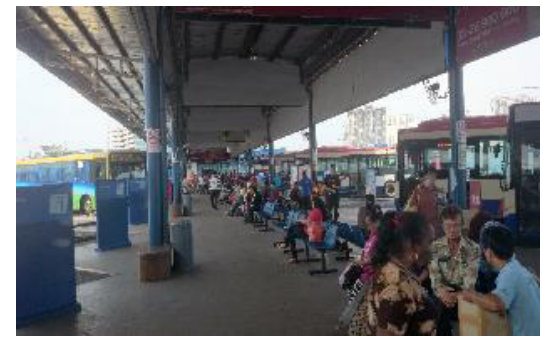

Figure 9: Waiting area with exposed bright surroundings

\subsubsection{Air Quality}

The air quality of all the areas inside the Penang Sentral bus terminal are subjected to dissatisfaction, with highest dissatisfaction level in the toilet area and lowest dissatisfaction level at the escalators. This is mainly because of the exposed condition of the escalator area where air ventilation is stronger with better air flow and air freshness as shown in Figure 10. In comparison, the toilet area has poorer air quality.

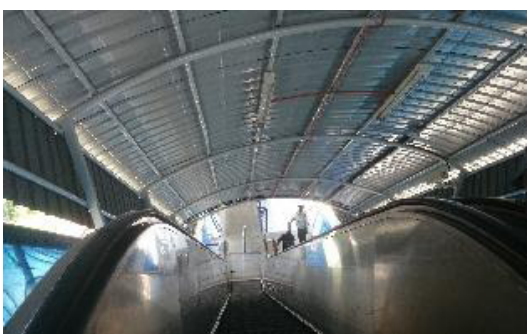

Figure 10: Escalator area with better air ventilation 


\subsubsection{Cleanliness}

The toilet was observed to be the most dissatisfied area in the matter of cleanliness. Both the areas were set up with dustbins to prevent people from littering anywhere. The floor of the toilet was wet. The wall and ceiling inside the toilet had some stain marks which gave people a feeling of dirtiness. As for the waiting area and escalator, the cleanliness was better.

\section{Conclusions}

The purposes of this study were to examine the relationship between the level of the maintenance management services related to the indoor environmental quality and the occupant satisfaction level, and to acknowledge the level of the building maintenance management services provided by the Penang bus terminal and their respective occupant satisfaction. The key conclusions drawn from this research are as follows:

1) Both investigated bus terminals are still not up to the satisfaction level. Occupants are still trending towards dissatisfaction in the Penang Sentral bus terminal with a little extent of satisfied in the Sungai Nibong bus terminal.

2) The level of maintenance management services and occupant satisfactions are higher in the Sungai Nibong bus terminal compared to the Penang Sentral bus terminal.

3) There might be a possible relationship between the maintenance management services level and occupant satisfaction level, where the higher the maintenance management services level, the higher the occupant satisfaction.

4) Air quality is a major issue that requires extra maintenance management in public buildings.

\section{References}

1. Suffian, A. (2013). Some Common Maintenance Problems and Building Defects: Our Experiences. Procedia Engineering, 54, 101-108.

2. Lateef. (2010). Case for alternative approach to building maintenance management of public universities. Journal of Building Appraisal, 5(3), 201-212.

3. Fisk, W. J., \& Rosenfeld, A. H. (1997). Estimates of improved productivity and health from better indoor environments. Indoor air, 7(3), 158-172.

4. Kwon, S.-H., Chun, C., \& Kwak, R.-Y. (2011). Relationship between quality of building maintenance management services for indoor environmental quality and occupant satisfaction. Building and Environment, 46(11), 2179-2185.

5. BSI. (1964) British Standard BS 3811: 1964 - Glossary of Maintenance Management Terms in Terotechnology. British Standards Publishing Ltd.

6. Lateef, Khamidi, M. F., \& Idrus, A. (2011). Appraisal of the building maintenance management practices of Malaysian universities. Journal of Building Appraisal, 6(3), 261-275.

7. Miles, D., \& Syagga, P. (1987). Building maintenance: a management manual: Intermediate Technology pub.

8. Syce, M. (2006). Designing for maintenance. Metropolitan University, Nelson Mandela. 